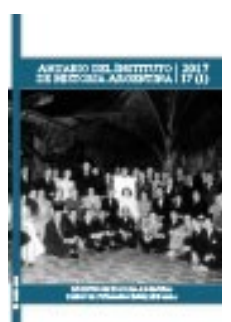

Anuario del Instituto de Historia Argentina, vol. 17, nº 1, e034, junio 2017.

ISSN 2314-257X

Universidad Nacional de La Plata.

Facultad de Humanidades y Ciencias de la Educación.

Centro de Historia Argentina y Americana

\title{
Representantes y representaciones de Argentina en la Organización Internacional del Trabajo en la década de 1920
}

\author{
Argentine's representatives and representations in the \\ International Labor Organization on the 1920's
}

\section{Andrés Stagnaro *; Laura Caruso **}

* Instituto de Investigaciones em Humanidades y Ciencias Sociales - Universidad Nacional de La Plata - CONICET; ** Instituto De Altos Estudios Sociales - Universidad Nacional de San Martin - Universidad de Buenos Aires - CONICET, Argentina | andres.stagnaro81@gmail.com; lauracaruso@gmail.com

\section{PALABRAS CLAVE}

Organización Internacional del Trabajo Representantes

Argentina

\section{KEYWORDS}

International Labor

Organization

Representatives

1920

Argentine

\section{RESUMEN}

El artículo aborda la relación de la Argentina y la Organización Internacional del Trabajo (OIT) a través de los distintos representantes que concurrieron a las Conferencias anuales del organismo durante la década del veinte del siglo pasado, en momentos en que la OIT estaba en proceso formativo. Los informes que estos delegados hicieron públicos -en el caso de los delegados gubernamentales informes elevados a las autoridades, en el caso de los delegados obreros y patronales publicados en diversos medios- permiten analizar las expectativas que portaban al interactuar en un organismo internacional que tenía sus propios objetivos. En muchos casos la OIT fue un escenario más en la disputa entre el estado, los patrones y los obreros, y en otros se puede percibir la uniformidad de criterios en relación a algunos tópicos particulares, tales como el lugar de la Argentina en relación a su legislación laboral. Al mismo tiempo, la participación de las delegaciones argentinas exigió la adecuación del sistema de relaciones establecido entre los sindicatos y el Estado ya que, ante la ausencia de un mecanismo formal en la elección de los representantes obreros, este fue reemplazado por mecanismos ad hoc en los que primaba la coyuntura de conflictividad local.

\begin{abstract}
The article approach the relations between the Argentine and the International Labor Organization (ILO) through the different argentine 's representatives on the ILO's annual conferences during the formative process on the 1920's. The representative's reports -in the case of the government's representatives those reports were raised to the authorities, in the case of the workers and employers delegates the reports were published in different publications- allowed us to analyze those delegates expectations while they interact with a an organizations with their own objectives. In many cases the ILO was just another stage in the dispute between the state, the workers and the employers, in others we will be able to see the uniformity of criteria in some topics, such as the spot of argentine's labor legislation. At the same time, Argentine's participation on the ILO's conferences demands the adequacy of the relations system between the State and the workers unions. In the absence of this kind of mechanism the workers representative elections depends on the moment of local labor unrest.
\end{abstract}


La década del veinte del siglo pasado fue un momento de ebullición en la actividad de la Organización Internacional del Trabajo (OIT) en Latinoamérica. El punto culmine de esta febril actividad fue la visita que el entonces director del organismo, el francés Albert Thomas, realizara a los países de la región del Cono Sur en 1925 en búsqueda de apoyos a las iniciativas de la organización y para favorecer la ratificación de los convenios que la misma había promulgado durante sus primeras conferencias anuales. Este viaje también implicó un cambio en la concepción que la propia OIT, y principalmente su director, tenían en torno a la región (Ferreras, 2011). Al mismo tiempo favoreció un abandono parcial del eurocentrismo al que habían abonado las instituciones laborales previas, e incluso la propia OIT durante sus primeros años, en las que solo Argentina -un país eurófilo- logró cierta presencia al garantizar delegaciones completas -es decir con representantes del estado, la patronal y los obreros- en los primeros dos congresos en Washington (1919) y Génova (1920). (Stagnaro 2017).

El dispar éxito en el objetivo primario -lograr la ratificación por parte de los países del Cono Sur de las convenciones adoptadas en las conferencias- fue, sin embargo, parcialmente superado pon el establecimiento de una serie de contactos o informantes claves que, si bien en muchos casos ya venían tejiendo redes de colaboración en el ámbito internacional, encontraron en la OIT una institución dispuesta a recibirlos y situarlos en un lugar de cierta preponderancia.

Se propone aquí presentar, a partir de diversas fuentes documentales, quienes fueron los que constituyeron estas redes. Actores centrales en la lógica tripartita del organismo, los delegados a las conferencias anuales se constituyeron en los núcleos de las redes. Y en algunos casos incluso su participación en las conferencias transmutó en funcionarios del organismo. Al mismo tiempo la presencia de la OIT fue también constatada por diferentes actores que vieron en el desarrollo del organismo una oportunidad para obtener apoyo a sus causas particulares -como fue el caso de trabajadores de sectores específicos como los marítimos- (Caruso, 2014). Significativa resulta la postura de diversas organizaciones sindicales que oscilaron entre el apoyo y la desconfianza en relación a los objetivos propuestos por la OIT. Las diferencias ideológicas, las peculiaridades y variopintas formas de vinculación entre los sindicatos y el Estado, no impidieron que distintos dirigentes sindicales asumieran el rol de representantes obreros ante la OIT, distinguiendo con su presencia a las delegaciones argentinas. Nos proponemos indagar, a través de tales representaciones, los acuerdos, los conflictos y alineamientos ideológicos del sindicalismo a nivel local e internacional, los que muchas veces tensionaron el carácter armónico que la propia OIT concebía como central en su funcionamiento tripartito.

En el caso de las representaciones estatales, estas se desenvolvieron con mayor estabilidad y algunas figuras del funcionariado argentino se transformaron en referencias ineludibles. Sin dudas Alejandro Unsain fue el personaje casi excluyente en la década del veinte, siendo el gran promotor del desarrollo del derecho del trabajo en Argentina con una fuerte impronta internacional. Otras figuras, como Carlos Saavedra Lamas o Leónidas Anastasi, se fueron constituyendo, a partir de su vínculo con la OIT, en fuertes referencias locales y regionales, llegando el primero a ser presidente de la conferencia anual del organismo realizada en Ginebra en 1928. Así el análisis de sus informes nos permitirán dar cuenta también de las expectativas que en términos de política internacional se trazaban los gobiernos argentinos.

\section{La Argentina en la OIT: entre el país modelo y la situación especial.}

Argentina adhirió a la Organización Internacional del Trabajo el 28 de Junio de 1919 cuando la organización estaba dando sus primeros pasos formales, y por esto aún hoy se la considera miembro fundador. La OIT hundía sus raíces en los primeros intentos organizativos de fines del siglo XIX, aunque su impulso definitivo 
llegó durante el conflicto bélico europeo, cuando algunas de las propuestas de la Asociación Internacional para la Legislación Laboral fueron retomadas en el título XIII del Tratado de Versalles (Van Daele, 2010). Este origen europeo $-\mathrm{y}$, en ese momento, con fuerte apoyo norteamericano a través del presidente de la American Federation of Labour (AFL) Samuel Gompers- había excluido a los países latinoamericanos, con la excepción de Cuba que sí participó de las rondas preliminares. Esto no impidió que la Argentina rápidamente adhiriese al organismo ni que su presencia en la OIT perdurase, a pesar de los vaivenes que el país tuvo en relación a la Sociedad de Naciones, de la que la OIT formalmente formaba parte.

El vínculo entre la Argentina y la OIT partió de acercamientos entre algunos de los que serían los interlocutores locales y distintas instancias organizativas previas que constituyen el camino que la propia institución estableció como sus antecedentes inmediatos. Estos denotan, en realidad, parte de su propia ideología, que contempla la acción sobre la cuestión social como progresiva y acumulativa, tal como sostiene Norberto Ferreras (2011). Esta ideología era compartida por los funcionarios que fungieron de nexo entre la OIT y la Argentina. Es decir: si bien los antecedentes de la OIT eran fundamentalmente europeos, estos intentos previos habían buscado, sin éxito aparente, expandir sus esferas de acción dentro del mundo occidental industrializado. En ese contexto, entre fines del siglo XIX y la Primera Guerra Mundial, la Argentina -específicamente las ciudades de la zona pampeana- era un foco de especial atención ya que contaba con un notorio crecimiento industrial y podía mostrar ciertos indicadores -urbanización, capacidad industrial, consumo, etc.- que la colocaban como un país "moderno”. Esto permitió a varios referentes de la escena política vernácula ser parte de los intentos de expansión de la predecesora de la OIT, la Asociación Internacional para la Protección de los Trabajadores, una organización de carácter privado que buscaba homogeneizar la legislación social a escala planetaria. Esta asociación estableció vínculos con países no europeos -Argentina, sí, pero también Chile (Yañez, 2000)- y fundamentalmente con los países que contaban con oficinas dedicadas al trabajo.

Por tanto, cuando se creó la OIT, importantes referentes argentinos en el campo del derecho social ya habían establecido vínculos más o menos estables e institucionales con sus pares de organismos europeos. Tales vínculos personales reforzaron lo que eran ya fuertes lazos académicos. Es menester recordar que el Departamento Nacional del Trabajo (DNT), creado en 1907, era fundamentalmente un organismo de carácter técnico y académico (Suriano, 2012), y sus funciones estaban más orientadas a la construcción de estadística y la presentación de proyectos legislativos, quedando relegada su misión como agente de control. Este perfil del DNT potenció los intercambios con instituciones similares y su cuerpo de funcionarios estaba muy bien informado sobre las novedades en el campo legislativo social a nivel mundial, dando cuenta también de la escala global del fenómeno de la expansión legislativa en el ámbito laboral. $\underline{1}$

Esta expansión, y sobre todo en el marco ya de la Primera Conferencia de la OIT en Washington en Octubre de 1919, generó desavenencias en torno a la posibilidad de una aplicación internacional de las convenciones adoptadas por la conferencia. Las quejas se hicieron efectivas tanto desde algunos de los países más industrializados, por considerar que una desigual aplicación de las normas generaría competencia desleal en razón de los costos, como de los países menos industrializados -estos últimos suponiendo que una extensión de la legislación social desalentaría la promoción de la industrialización-. Aquí interesa abordar, al menos en forma acotada, la posición argentina en relación a este punto. Colocados frente a la disyuntiva sobre el debate de la extensión de una legislación de carácter universal, los delegados argentinos -fundamentalmente los delegados gubernamentales- rechazaron la posibilidad de incorporarse a los países en situaciones especiales. En palabras de Leónidas Anastasi y Felipe Espil: “en ningún caso, hemos creído que la República Argentina pudiera acogerse a estas disposiciones de naturaleza excepcional ya que su desarrollo industrial la coloca muy cerca de las principales potencias” (1920, p. 61). Sin embargo, esta postura no era monolítica y, ante la posibilidad que la segunda conferencia tratara sobre el trabajo agrícola, los mismos delegados 
afirmaron que era conveniente realizar una conferencia nacional a fin de estar preparados y no exponerse "a ser arrastrados a una legislación internacional que ignore nuestros fenómenos y situación especiales”, en tanto que "las soluciones alcanzadas tienen sobre todo en vista los intereses europeos ignorando los de otros países” (1920, p. 86).

Similar postura se observa en los informes del asesor técnico de la delegación en Washington, Alejandro Unsain. Tanto en los informes oficiales de las dos primeras conferencias $\underline{2}$ como en diversos escritos, Unsaín remarca la importancia de las conferencias en pos de una normalización universal de la legislación del trabajo, al tiempo que destaca lo avanzado de las leyes argentinas -y de esta forma el grado de modernidad del país-.

Esto permite dilucidar cuál era la representación que sobre el país reflejaban los delegados a la OIT: un país moderno e industrializado cuya legislación estaba en sintonía con los más avanzados del mundo. De esta forma, Argentina se diferenciaba de aquellos países que debían ser tratados con consideración especial. Pero al mismo tiempo esta autorepresentación se encontraba amenazada por las posibilidades de avances concretos de la OIT sobre temas específicos que pudiesen cuestionar o poner en duda ese grado de modernidad, como en lo referente al trabajo agrícola, en el que la especificidad argentina era esgrimida como forma de establecer una barrera defensiva.

Esta autorepresentación como nación moderna fue postulada por medio de una fuerte campaña proselitista que incluyó la distribución entre los concurrentes a la conferencia de Washington de un volumen con las leyes argentinas, así como los proyectos en consideración. $\underline{3}$ Además, se sustentaba en estos vínculos previos establecidos con los organismos antecesores de la OIT, es decir que los delegados podían presentarse como parte de una tradición en la temática. Igual de importante en la proyección de una representación en tanto país moderno e industrializado fue la presentación de delegaciones completas en las dos primeras conferencias internacionales del trabajo. Esto implicaba la posibilidad de cumplir con un aspecto central en el proyecto ginebrino, la representación tripartita (estatal, empresarial y obrera) que permitía encontrar un sustento externo a su autorepresentación al justificar la madurez del país en las relaciones industriales. Esta capacidad de asistir y mostrar una delegación conduce a la pregunta en torno a quiénes eran los representantes argentinos ante la OIT, y si compartían o no esta representación de la Argentina como país moderno.

\section{Delegados y correspondientes: los representantes argentinos en la OIT}

Desde el momento de su creación y hasta hoy, en plena celebración de su próximo centenario, la OIT ha desplegado como baluarte de su construcción política el mencionado tripartidismo. Dicha representación igualitaria entre estados, empresarios y trabajadores a través de sus respectivas organizaciones fue considerada un signo de la participación democrática y garante de la paz buscada en 1919. Esta composición de las conferencias internacionales y de su órgano de gobierno, el Consejo de Administración, llevó aparejada una mayor eficacia y legitimidad en sus resoluciones, si bien no garantizó -ni garantiza- su aplicación o puesta en práctica.

La OIT es así la única institución internacional en cuyos debates y decisiones participan actores extragubernamentales, con una estructuración basada en la idea de colaboración de clases y consenso social. Constituyó para las representaciones gremiales, en palabras de algunos de sus estudiosos, un instrumento muy importante para la consecución de sus objetivos, soliendo tener un perfil y programa mucho más activo, frente al rol de freno a diversas iniciativas desplegado por los empleadores, metáfora que llevó al primer director general de la OIT, Albert Thomas, a afirmar: "no es necesariamente un insulto, pues una locomotora sin frenos tiene pocas posibilidades de llegar a su destino” (Rodgers, Lee, Swepston y Van Daele, 2009, p. 
18). La participación tripartita, como signo distintivo de esta agencia internacional de la posguerra, puso de manifiesto la necesidad de construir consensos y legitimidades en un mundo convulsionado por la revolución en los años de la Primera Guerra Mundial. De la mano de esta representación se construyó una noción de trabajo que apuntaba a su desmercantilización y a una condición de sujeto trabajador(a) asociada a ciertos derechos y regulaciones, que fueron objeto de múltiples construcciones, jerarquizaciones y exclusiones, según el caso.

Lejos de convertirse en un actor por sobre otros, la OIT fue un sujeto más, tornándose en una nueva dimensión de disputas y tensiones, así como el escenario propicio para ciertos acuerdos, cuya influencia e impacto varió en el mediano plazo, desplegando en su devenir usos dispares, contradictorios y coyunturales de ese espacio tensionado por los diversos actores que lo constituyeron.

Por razones en algún punto obvias, es más lo que se sabe sobre los delegados gubernamentales o técnicos ante la OIT que sobre los delegados obreros o patronales.

En primer lugar, porque los primeros realizaron una acción consciente por dejar registro de su relación con el organismo, ya sea por obligaciones del cargo -los informes oficiales- como por intereses intelectuales. Segundo, porque los delegados gubernamentales y los delegados técnicos lograron cierta estabilidad en el vínculo con la OIT. Así, mientras los delegados obreros, e incluso los patronales, mantenían una relación distante con el organismo y limitaban su participación a las conferencias anuales, los delegados técnicos continuaban relacionados en el Consejo de Administración de la Oficina Internacional del Trabajo -el Bureau-, el órgano administrativo permanente de la OIT, y participaban de un intercambio fluido con otros cuadros técnicos. Por caso es conocida la trayectoria de Alejandro Unsain, $\stackrel{4}{a}$ quien mantuvo una estrecha colaboración con la OIT desde la primera conferencia internacional en Washington y fue miembro permanente del Consejo por la República Argentina, llegando a vivir en Ginebra. Su colaboración con la OIT se consolidó durante toda la década del veinte y llegó a ser corresponsal de la OIT en los años treinta.

Aun así, es significativo que los delegados obreros a las conferencias tuvieran cierta continuidad, repitiéndose algunos nombres, ya sea como delegados o como asesores técnicos de la representación obrera, como los casos de Américo Juan Baliño —en 1919 y en 1924- o José Negri -1924, 1934 y 1935-,Juan Brennan -1927 y 1933-. $\underline{5}$ En el caso de los delegados patronales la estabilidad que no se encuentra en los nombres -con la excepción de Atilio Dell Oro Maini- reside en las instituciones: por lo general la representación patronales es delegada en la Unión Industrial Argentina (UIA), quien designa a veces en solitario y otras en acuerdo con otras instituciones patronales, como la Asociación del Trabajo, a sus delegados.

Interesa revisar de forma sucinta el mecanismo por el cual se designaba a los delegados. Aunque sugerido por distintas organizaciones, correspondía a las autoridades del Poder Ejecutivo Nacional ratificar y comunicar a la OIT, a fin de tramitar las credenciales, los nombres del conjunto de los delegados. En principio la elección debía darse en el marco del artículo 389 del título XIII del tratado de Versalles: los estados miembros estaban obligados a elegir a los delegados no gubernamentales entre las organizaciones profesionales más representativas del país (OIT,1929, p. 5 y ss.). Este mecanismo generó frecuentes inconvenientes a distintas delegaciones de los países miembros a lo largo de la historia de las conferencias anuales de la OIT. Las más de las veces, impugnaciones de orden ideológicas por parte de distintas agrupaciones sindicales se escondían detrás de la acusación sobre la falta de representatividad de los delegados designados, como se verá en los casos de los delegados obreros más adelante.

Un caso emblemático fue la designación de los representantes obreros en 1925. La elección de miembros de los círculos católicos despertó nuevamente quejas por el incumplimiento de la representatividad exigida en 
el artículo 389. A partir de allí el Ministro del Interior, Vicente Gallo, decidió dictar una resolución para establecer el mecanismo de elección de los delegados no gubernamentales (CMDNT, 1925, p. 1076). Este implicaba que el DNT enviara al ministerio una lista con las organizaciones obreras y patronales más importantes en funcionamiento, su dirección, situación legal, número de adherentes, etc., 60 días antes de la Conferencia Anual de la OIT. A partir de este listado el ministerio indicaría a qué organizaciones invitar a la conferencia, dando un plazo de 10 días para contestar. En caso de contestar afirmativamente, el Ministerio de Relaciones Exteriores se encargaría de notificar a la OIT. La resolución administrativa no tuvo los efectos políticos deseados y no evitó las controversias sobre las designaciones, que se continuaron durante toda la década del veinte. Aun así, el dispositivo permitió a las autoridades evitar cuestionamientos en el seno de las conferencias. Esta resolución fue objeto de revisiones y para 1927 Alejandro Unsain, en esos momentos establecido en Ginebra, envió al Ministro las interpretaciones del artículo 389 dadas por la Corte Permanente de Justicia Internacional (CMDNT, 1927, p. 2259). De esta forma se adecuó a las normas del organismo y evitó los cuestionamientos externos.

\begin{tabular}{|c|c|c|c|}
\hline & $\mathrm{Ans}$ & & \\
\hline 1919 & $\begin{array}{l}\text { Leónidasa nastasi, Fel ipe Espil, } \\
\text { Alejandro Unsain (t) }\end{array}$ & $\begin{array}{l}\text { Américo Juan Bali fo (La } \\
\text { Fraternidad) }\end{array}$ & $\begin{array}{l}\text { Hermene gildo Pini, Ale jandro } \\
\text { Joseph Hayes ( } t \text { ) }\end{array}$ \\
\hline 1920 & $\begin{array}{l}\text { Alfre do Col mo, Ale jandro Unsain } \\
\text { (t) }\end{array}$ & $\begin{array}{l}\text { Pedro Di Quattro (Federación } \\
\text { Obrera Maritima) }\end{array}$ & Atilio Dell Oro Maini \\
\hline 1921 & No presenta & No presenta & No presenta \\
\hline 1922 & No presenta & No presenta & No presenta \\
\hline 1923 & Personal Consular & & \\
\hline 1924 & $\begin{array}{l}\text { José León Rodeyro, Aleides } \\
\text { Calandrelli, Felipe Espil (t), } \\
\text { Lorenzo Amaya (t) }\end{array}$ & $\begin{array}{l}\text { José Negri, Américo Baliño (t) y } \\
\text { Juan Quani (t) (La Fraternidad) }\end{array}$ & $\begin{array}{l}\text { J.A. de Marval, Santiago Valle } \\
\text { Barraco (t) }\end{array}$ \\
\hline 1925 & $\begin{array}{l}\text { Agustin Araya y Julián Enciso, } \\
\text { Alejandro Unsain (t), Juan Bayetto } \\
\text { (t), wis Lauzet (t) }\end{array}$ & $\begin{array}{l}\text { Carlo Y. F. Coneil, Santiago Valle } \\
\text { Barraco (t) (Aspociadión Catolica } \\
\text { de Trabajadores) }\end{array}$ & Atilio Dell Oro Maini \\
\hline 1926 & No presenta & Nopresenta & No presenta \\
\hline 1926 Maritima & Alejand ro Unsain y Luis Magnanini & $\begin{array}{l}\text { Viola (Union Obrera Maritima y } \\
\text { Centro de Capitanes), Ramón } \\
\text { Suárez }\end{array}$ & \\
\hline 1927 & $\begin{array}{l}\text { Carlos Saavedra Lamas (re nuncia, } \\
\text { reemplazado por Alejandro } \\
\text { Unsain), Juan Bayetto (t), Luis } \\
\text { Magnanini (t) }\end{array}$ & $\begin{array}{l}\text { Juan B. Quiani, Cip riano Barre iro } \\
\text { (t), Juan Brennan (t) } \\
\text { (Confederaciōn Obre ra Argentina) }\end{array}$ & Jorge Magnin, Dionisio Mongay (t) \\
\hline 1928 & $\begin{array}{l}\text { Carlos Saavedra Lamas, Carlos } \\
\text { Aceve do }(\mathrm{t}) \text {, Octavio Rubio }(\mathrm{t}) \text {, } \\
\text { Orestes Confal onieri (t) }\end{array}$ & $\begin{array}{l}\text { Bernardo Be cerra, Jose Macotta } \\
\text { (t), Camilo Mollo (t), Enrique } \\
\text { Diosdado (Confe dración Obre ra } \\
\text { Argentina) }\end{array}$ & $\begin{array}{l}\text { Lorenzo Amaya (acuerdo entre } \\
\text { Unión Industrial Argentina y } \\
\text { Asociación del Trabajo) y Desiderio } \\
\text { Guillot (t) }\end{array}$ \\
\hline 1929 & No presenta & Nopresenta & Nopresenta \\
\hline 1929 Maritima & No presenta & No presenta & No presenta \\
\hline 1930 & No presenta & No presenta & No presenta \\
\hline
\end{tabular}

(t): asesor téenico

Fuente: Ela boración propia en base a distintas fuentes documentales

\section{Delegados obreros}

En este caso, interesa indagar el rol de los delegados obreros. Si es claro que, en tanto nuevo campo de construcción política, la OIT constituyó la apertura de novedosas herramientas y posibilidades para las organizaciones del mundo del trabajo, menos directa y lineal fue la participación y aceptación de la entidad por las diversas centrales internacionales de trabajadores de la primera posguerra, situación que se reprodujo al interior de los gremios y federaciones de cada país, incluida la Argentina. Como muestra el trabajo de Pilar Calvo Caballero para el caso español en los años de la presidencia en la OIT de Albert Thomas (1919-1932), 
las actitudes de patrones y obreros en un momento fundacional e inestable fueron disímiles entre sí, algo esperable, pero también lo fueron al interior de cada grupo, y con variaciones en el tiempo. En el caso de los delegados obreros se tejió una colaboración, entre el respaldo y la desconfianza, no carente de tensiones entre los gremios y el socialista francés Thomas, director del organismo ginebrino. Tal respaldo cristalizó en un conjunto de manifestaciones, desde la invitación a congresos, conferencias y espacios gremiales, hasta las corresponsalías, las cuales no prescindieron de negociaciones y condicionamientos, desplegando los representantes obreros estrategias diversas y complementarias, desde la solidaridad internacional y el repliegue nacional ante la OIT, al cuestionamiento y abierto boicot a su labor. Si la autora encuentra la clave explicativa del afianzamiento de la OIT en la capacidad y éxito de la obra del gabinete de Thomas y su figura, a través de sus viajes, propaganda y red de corresponsales, interesan aquí las apropiaciones, usos y posiciones desplegadas por los gremios a la hora de pensar su participación en la conformación de una particular “communitas” normativa en términos de la regulación laboral (Ferreras, 2012).

Como representación en construcción, las delegaciones obreras fueron un campo de disputa entre gremios y estados, por su presencia o prescindencia, dependiendo del caso y coyuntura histórica. Durante la primera década de existencia de la OIT, las definiciones de campos laborales con derechos reglados, las tipificaciones y definición del trabajo mismo, delimitando actividades susceptibles de derechos, fueron elementos de una disputa mundial y sectorial; pocas veces, como en el caso del trabajo marítimo, lograron hacer prevalecer su especificidad y preponderancia, de la mano de los intereses de los países centrales (Caruso, 2017).

Así también, la designación, composición y acción de las delegaciones obreras fueron tramas coyunturales donde, tanto las posiciones político ideológicas de ciertos gremios, como su lugar dentro del conjunto del movimiento sindical nacional y su vinculación con el gobierno, tuvieron un papel significativo a la hora de definir nombres y pasajes. Tal fue el caso del delegado obrero en la Conferencia de Washington en 1919. La designación de Américo Juan Baliño, secretario-gerente de La Fraternidad y vinculado al Partido Socialista, $\underline{6}$ fue objetada por la comisión de credenciales, asunto que ocupó gran parte de las deliberaciones de la jornada del 21 de noviembre de 1919.

Su caso resulta emblemático porque, como se desprende de las actas de la conferencia, al tratarse de una institución que recién comenzaba a andar, este tipo de circunstancias no solo la ponían a prueba, sino que sentaban precedentes para el futuro de la organización. En efecto, esa tarde se discutieron dos temas de importancia, ambos relativos a la organización de la conferencia y la representatividad de los delegados: el primero, si correspondía a los países miembros que no contasen con la delegación completa poder votar con sus delegados presentes -propuesta presentada por el representante del gobierno portugués y aprobada--, y el segundo, sobre las bases en las que debía elegirse los miembros no gubernamentales.

A pesar de que la comisión de credenciales rechazó otros delegados, por caso el delegado obrero de Guatemala, tal situación no llegó al pleno de la conferencia. Pero la excepcionalidad del caso del delegado obrero argentino llamó la atención en tanto que su designación exigió una interpretación sobre el carácter representativo de su organización, requerido en el citado artículo 389 del Tratado de Versalles. Para los miembros del comité de credenciales no había dudas de que Baliño era representativo de un "sector" de los trabajadores argentinos, sin embargo, la objeción minoritaria sostenía que no era de una central sindical, sino de un sindicato particular, siendo que existían en Argentina "diferentes organizaciones de más o menos el mismo tamaño e influencia” (OIT,1920, p. 109)ํㅡ y no se había realizado una consulta al resto de las mismas. Hasta aquí, el reclamo pasaba por una cuestión de forma, e incluso el miembro informante de la comisión de credenciales, Sir Malcom Delevigne de Gran Bretaña, sugería no tomar ninguna resolución al respecto. Sin embargo, el representante obrero por Holanda, J. Oudegeest, quien era además el secretario de la Federación Sindical Internacional, hegemonizada en la posguerra por una orientación socialdemócrata (Godio y Wachendorfer, 1986), presentó de forma enfática la posición de la minoría en el comité de credenciales. En 
una primera instancia, Oudegeest opuso a la designación de Baliño la existencia de una central obrera cuyos adherentes calculaba en unos 80.000 según sus informantes, o en 20/30.000 en el peor de los casos, pero que de todas maneras superaba los 15.000 que presentaba La Fraternidad. Por lo tanto, sin nombrarla, consideraba que le correspondía a la Federación Obrera Regional Argentina (FORA) el carácter de representatividad de los trabajadores, y no a La Fraternidad. Además, aducía que, no existiendo una ley de asociaciones profesionales en Argentina, ni la FORA ni La Fraternidad contaban con un aval legal, y que, de todas formas, esto no era un indicador fiable, ya que su propia organización obrera no contaba con un aval legal por parte del gobierno holandés y sin embargo eso no restaba representatividad. Además, desconocía el dictamen de la mayoría que aducía que la FORA tenía una existencia inestable. Su argumento se centraba en sus propios vínculos personales/sindicales con los militantes de la FORA ya que, sostenía con algo de ironía,

En este momento tiene a dos de sus miembros, el secretario y el tesorero, haciendo un viaje por Europa comisionados por su organización para estudiar las diferentes formas de organización sindical existentes en los países europeos. Estoy sorprendido que se sostenga que dicha organización tiene una vida efímera cuando envía a dos hombres a visitar Europa por seis meses (OIT, 1920, p. 110).

Su posición fue apoyada por el delegado gubernamental francés, principalmente debido a que su delegado obrero también fue observado por la comisión de credenciales por razones similares, aunque el caso no se trató en el pleno de la Conferencia.

La defensa de Baliño por parte de la delegación del gobierno argentino fue asumida por Leónidas Anastasi, quien sostuvo en pocas palabras la importancia de La Fraternidad en términos numéricos y simbólicos, y además adujo que, a diferencia del caso francés, donde existía una central de trabajadores fuertes, en Argentina no existía una, sino tres y débiles: la FORA, la FORA del V Congreso, y la Organización de Obreros Católicos. Por todo esto sostenía que rechazar al delegado obrero

herir ía a un gobierno que se ha esmerado por llevar adelante el ideal de la Sociedad de Naciones y de la Organización Internacional del Trabajo para el beneficio [...] de las masas de hombres que, habiendo contribuido con su trabajo al bienestar de la comunidad, ahora solo tienen pobreza y miseria en su haber (OIT, 1920, p. 111). $\underline{9}$

Baliño mismo tuvo la posibilidad de hablar en el pleno y asumió su defensa, la de su organización “y al

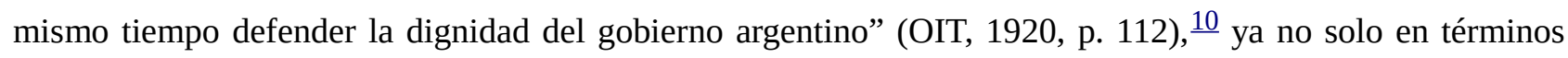
numéricos, sino de lo que consideró una razón moral. Su principal defensa se basó en la comparación entre los logros de la FORA y los de La Fraternidad, tanto en la extensión de la organización como en las condiciones económicas logradas para sus miembros. Pero además su representatividad se vinculaba a la aceptación del estado avanzado de las relaciones industriales argentinas, fundamental para la autorepresentación de la delegación, ya que estos logros fueron conseguidos por mecanismos legales y La Fraternidad "nunca utilizó su poder en detrimento del bienestar económico nacional” (OIT, 1920, p. 112). $\underline{11}$ En este sentido, la elección de La Fraternidad estuvo vinculada a su accionar en el campo legalista, condición que según Baliño compartían con otro gran gremio que fue consultado a la hora de elegir al delegado obrero: la Federación Obrera Marítima (FOM). Es evidente la comunión en los ideales perseguidos, tanto por el representante gubernamental como por el representante obrero argentino, en relación a la imagen modélica que la delegación buscó desplegar en las conferencias internacionales. Finalmente, el delegado argentino fue aceptado y la Argentina se convirtió en uno de los pocos países en contar con una delegación completa en la Conferencia, el único de los 15 países latinoamericanos. $\underline{12}$

En la segunda conferencia internacional, realizada en la ciudad portuaria de G énova a mediados de 1920, el 
delegado sindical Pedro Diquattro representó a los dos principales gremios del sector embarcado. De los países latinoamericanos presentes -Chile, Venezuela y Uruguay- Argentina fue la única en enviar una delegación completa. Estos delegados no participaron del debate en las comisiones sobre temas particulares, informes y proyectos, debido a su tardía y controversial designación. Así, los delegados Alfredo Colmo, Alejandro Unsain, Pedro Di Quattro y Atilio Dell'Oro Maini llegaron a finales del mes de junio, ya que su designación estuvo estrechamente vinculada al conflicto marítimo en desarrollo en el puerto de Buenos Aires (Caruso, 2011). La FOM y el Centro de Capitanes de Ultramar protagonizaban entonces una coyuntura huelguística peculiar, en la cual construían una alianza promisoria para la tan mentada unidad del mundo obrero de a bordo. Así, la elección del Capitán de Ultramar Pedro Diquattro cobró relevancia. Este genovés de nacimiento, radiotelegrafista primero, piloto y luego capitán al llegar a la Argentina, fue miembro fundador del mencionado Centro en el año 1918, y a la vez que representó a los marítimos en la OIT lo hizo como primer delegado ante otro organismo internacional, la Federación Internacional del Transporte (ITF), organización internacional sindical fundada en Londres en 1896. El espacio de la OIT permitió su participación y reunión con los delegados obreros de Francia, Italia e Inglaterra, hilvanando así solidaridades para el conflicto obrero en puertos argentinos.

En Génova se determinó la organización en forma separada de conferencias marítimas, ante la especificidad y relevancia de este tipo de labor. A tales conferencias asistieron delegados de gremios vinculados al sector, destacándose el hecho que en 1920 fue la FOM el sindicato representado, producto de su crecimiento, visibilidad y trascendencia, cuya asistencia estuvo en entredicho como forma de presión y negociación con el gobierno y las empresas en plena huelga marítima.

La ausencia de representación gremial en las conferencias realizadas en Ginebra en 1921 y 1922 no sorprende, en función de la represión y realineamiento generado desde el gobierno argentino con el movimiento obrero local, lo cual se prolonga hasta 1923, donde sólo concurren representantes gubernamentales -ver cuadro-. Nuevamente serán los gremios más fuertes del transporte, y en este caso el ferroviario, los que compondrán la delegación obrera a la conferencia de 1924. Los tres dirigentes, José Negri, Américo Baliño y Juan Quani, representaban al particular gremio ferroviario de La Fraternidad (Gordillo, 1988 y Suriano, 1991). Negri, malagueño de origen, llegado al país en 1905, ingresó en Rosario a trabajar en la Compañía General de Ferrocarriles, llegando a ser miembro en diversas oportunidades de la dirección de los gremios del sector, en particular de la Unión Ferroviaria, creada en 1922. Fue además el primer secretario general de la COA, la central socialista (Troncoso, 1983, pp.158/189).

Esta delegación publicó su informe de la conferencia en la CMDNT. Interesa resaltar no tanto el aspecto técnico, sino las apreciaciones en torno a la extensión de la autorepresentación argentina. Al dar cuenta de la III y IV Conferencia, los representantes obreros sostuvieron que, debido a la delegación en los miembros del cuerpo consular "no pudo tenerse en esa forma, una participación tan activa y directa como correspondía a la importancia del país” (CMDNT, 1924, p. 1433). Dicha importancia se sustentaba, según la delegación obrera, en las conferencias de Washington y Génova donde los representantes argentinos "sostuvieron los principios más humanos y democráticos” y

demostraron que hasta tanto Estados Unidos no se decida a abandonar sus escrúpulos [...] la República Argentina será en América la nación que con más eficacia interprete y realice el pensamiento concretado en la parte XIII del tratado de Versalles (CMDNT, 1924, p. 1433)

Además de la extensión de la autorepresentación argentina en el organismo, los delegados obreros también reforzaron en su informe la propia ideología de la OIT en su proyecto integrador conciliatorio del conflicto de clases. Su insistencia en la delegación completa era presentada como la única oportunidad para lograr la imparcialidad necesaria, la coordinación y cooperación para que los resultados obtenidos en la conferencia 
tuviesen validez, legitimidad y aplicación práctica.

En el año 1925 la Asociación Católica de Trabajadores (Círculos Católicos Argentinos) consiguió la representación nacional ante la OIT, enviando a un delegado obrero, Carlos Y. F. Conei, y un asesor técnico gremial, Santiago Valle Barraco, quien presidía la Asociación Ferroviaria Nacional, un ente propatronal del sector. Ambos nombramientos por parte del presidente Alvear suscitaron no pocas críticas. Incluso fue impugnada dicha representación vía telegrama por el gremio Confraternidad Ferroviaria, que presentó el caso ante la comisión de actas que daba inicio a la conferencia y acreditaba las representaciones. También La Fraternidad impugnaba esta designación en uno de los números de su publicación, donde sostenía: "no representa a la clase obrera”. Aún más, denunciaban la imprudencia del gobierno nacional al mostrar a los congéneres europeos este tipo de personajes, con el riesgo de que los obreros del mundo crean que en Argentina “no tenemos más que sacristías y elementos amarillos” (La Fraternidad № 335, 1925, p. 15).

Sin embargo, no fue considerado el pedido al carecer del respaldado con la documentación necesaria, y no tuvo consecuencias en la conferencia, como si sucedió en el caso del delegado obrero de Rumania, quien fue reconocido ante los datos acreditados de sindicatos y trabajadores afiliados (Lauzet, 1925, p. 189). La representatividad sectorial y numérica probada de manera eficaz parecía un argumento de peso a la hora de tener voz y presencia. Un caso diferente y de prolongado debate fue el del delegado obrero Rossoni, presidente de la Confederación de Corporaciones fascista, cuya impugnación fue presentada por los principales gremios italianos, apoyada por la totalidad de las representaciones obreras y, en el caso argentino, por el delgado gubernamental Araya, con argumentos que esgrimían la defensa de la libertad sindical, inexistente en el país mediterráneo (Lauzet, 1925, p. 192).

$\mathrm{Al}$ año siguiente, en una nueva conferencia marítima realizada en Ginebra, la representación fue ejercida por otro gremio que competía directamente con la FOM. Precisamente en 1926 las cuestiones estrictamente vinculadas al mundo del trabajo marítimo volvieron al centro de la escena nacional e internacional, suscitando una nueva conferencia particular para tales temas, ad hoc de la reunión anual de carácter general, que se realizó en la sede de Ginebra. Una delegación completa representó a la Argentina, conformada por Alfredo Viola y Ramón Suarez en su sector obrero. El primero, nuevamente un capitán de ultramar, iba en representación de su Centro y de la Unión Obrera Marítima (UOM). Dicho gremio surgió en competencia con la FOM meses antes, y su origen era motivo de polémica entre el apoyo patronal y el auspicio estatal para gestionar el armado de las tripulaciones y constituirse en interlocutor y representante gremial. Su creación y la militancia de base posterior tensionaban el carácter gremial de la UOM. Su presencia en Ginebra ponía de manifiesto el corrimiento del centro de la escena de la FOM y su vínculo con el gobierno radical. A la vez, mostraban la precariedad de los mecanismos de elección de delegados no gubernamentales, los que, fijados por el ministro del interior Vicente Gallo solo un año antes, estaban por detrás de las necesidades políticas.

El caso de Suarez es más complejo. Siendo un prominente militante de la FOM hasta pocos años antes, en 1926 se había volcado a la actividad periodística y a la militancia nacionalista gallega (Díaz, 2008). Su designación como delegado llama la atención, a la vez que destaca su formación en temas laborales durante el período de su militancia gremial. A la conferencia anual de ese mismo año no asistió delegado argentino alguno, contrastando con la presencia completa en el debate marítimo. La vacancia de representación en la conferencia general se explica por el rechazo de la Unión Sindical Argentina (USA) a la invitación realizada por el Presidente del DNT, Luis García. La central sostuvo que ni delegados de la central ni de ningún gremio miembro asistirían por considerar a tal organismo "ajeno por completo a los intereses de la clase trabajadora", siendo aquel "un congreso donde se reúnen los enemigos históricos de la clase obrera para simular un interés de justicia” y por tanto donde "están demás los representantes de quienes sufren a diario los vejámenes del actual régimen de desigualdad alimentado por estos”, según afirmaba el secretario general 
Sebastíán Ferrer (USA, 1926, p. 40).

Tanto en 1927 como en 1928 la Confederación Obrera Argentina (COA), central vinculada al socialismo, logró la representación en Ginebra, con elevadas críticas por parte de sus competidoras dentro del movimiento obrero vernáculo. Entre la nutrida delegación argentina de 1927, de los 8 participantes, 3 lo hacían en representación obrera: Juan B. Quiani, Cipriano Barreiro y Juan Brennan, delegados por la COA que coincidieron además en su asistencia con el $4^{\circ}$ congreso de la FSI. Al año siguiente, junto al Ministro de Relaciones Exteriores, Dr. Saavedra Lamas, viajaron los delegados obreros Bernardo Becerra, José Marotta, Camilo Mollo y Enrique Diosdado. Ese año el presidente del DNT Luis García envió notas de invitación a varias organizaciones obreras y patronales. Entre las obreras se destacaban los Círculos Católicos Obreros, la COA y la Federación Gráfica Bonaerense. Teniendo en cuenta los antecedentes en relación a la USA no llama la atención su exclusión, amparado en que en ocasiones anteriores se la había invitado negándose ésta por tratarse, en los términos del DNT, de una organización “antelegalitaria” (sic). (CMDNT,1928, p. 2348). La exclusión de la USA también se debió a que se encontraba en situación precaria, según la mirada de dicho departamento. Caso similar enfrentaba la FORA, cuya fuerza era considerada en esos momentos puramente nominal. Entre las exclusiones también estaban los trabajadores del sector marítimo, tan relevantes en la representación obrera en los primeros años de la década. La tensión y competencia entre los dos sindicatos del sector, FOM y UOM, en pleno despliegue, junto al conflicto desarrollado por la primera ante la compañía Mihanovich, la empresa naviera más importante del país, redundaron, a diferencia del año 1926, en que el gobierno decidió excluirlos de los posibles invitados. El hecho de que ese año no se celebrara la conferencia marítima puede explicar su exclusión para 1928, aunque estos factores tal vez permitan explicar también la ausencia de delegación en la conferencia marítima del año 1929. Precisamente ese año se realizaron dos conferencias marítimas y una anual a las cuales no asistió representación alguna desde la Argentina.

Un trabajo pionero en la observación de la representación obrera argentina ante la OIT resaltaba su carácter inestable durante la primera década de existencia de la entidad internacional (Belloni Ravest, 1969). Hasta 1927 el autor define una etapa de desconfianza generalizada entre los gremios ante el organismo, salvo por La Fraternidad, que, como organización consolidada, atendía a las cuestiones internacionales y a este tipo de espacios. Cierto es que dicha representación, tanto desde los gremios, los empresarios y los gobiernos, fue inestable y disputada en aquellos años. Pero como vimos, tal inestabilidad no debe ser asimilada al desinterés, al combate abierto contra el espacio ginebrino, o a su total impugnación. Por el contrario, entre un grupo particular de gremios nacionales, la designación como miembros de la delegación argentina ante la OIT fue una trinchera de debate y negociación. La estabilidad de la representación argentina en general, y la obrera en particular, llegaría en los años de 1930, vinculado tanto a la formación de la CGT como a la ratificación por parte del gobierno de Argentina de los convenios y recomendaciones de Washington y Génova, así como del Tratado de Versalles y la propia OIT. La variedad de situaciones dadas en la representación obrera ante las conferencias previas muestra los diversos sectores que componían y competían al interior del movimiento obrero, sus estrategias disímiles, y la paulatina y contradictoria consolidación de un "gremialismo funcionarial” de ciertos dirigentes con vinculaciones personales con líderes mundiales y ginebrinos, que consolidaron un campo particular de construcción gremial a partir de su circulación internacional en esferas no netamente obreras.

La variabilidad de la presencia y participación de delegados argentinos ante la OIT es mensurable y zigzagueante; del envío de delegaciones completas en las dos primeras conferencias, a la ausencia de toda representación y el envío de delegados gubernamentales en ocasiones. A partir de allí la representación estatal y empresarial estuvo garantizada, no así la sindical, que fue motivo de controversia política intensa, como vimos, desde los inicios. La Argentina aparecía ante sus contemporáneos como el país más constante y sistemático del continente en la concurrencia y participación en estos espacios. 


\section{Un trabajador gráfico en la OIT: de delegado gubernamental a corresponsal}

A la VII Conferencia Internacional del Trabajo, realizada en Ginebra, $\underline{13}$ asistió una nutrida delegación argentina, completa en su composición, la cual contó con la representación obrera de un dirigente católico. Sin embargo, entre los 5 participantes viajó el destacado militante y activista sindical Luis Lauzet, quien formara parte de la corriente sindicalista revolucionaria en las primeras dos décadas del siglo XX en Argentina. Lauzet, nacido en Francia en 1887, se desempeñó al llegar a la Argentina, y probablemente antes también, como obrero gráfico y luego como traductor del francés. Migró hacia Santiago del Estero por falta de trabajo en plena crisis de la Gran Guerra, y sin mayor éxito, retornó a la ciudad de Buenos Aires y al gremio gráfico al poco tiempo. (Di Tella, 2003 p. 153 y ss.) Allí fue elegido como miembro del Consejo Federal de la FORA IX entre los años 1918 y 1921, de cuyo periódico, La Organización Obrera, fue editor responsable. Previamente, había sido el primer secretario de la Federación Gráfica Bonaerense, y colaborador de los periódicos del sindicalismo revolucionario La acción socialista y La acción obrera en la primera década del siglo XX.

El lugar híbrido de Lauzet, por su trayectoria gremial y su presencia en nombre del gobierno en la conferencia, lo presenta como una figura particular y constitutiva de esta incipiente burocracia internacional de técnicos y dirigentes, al calor del despliegue de la política ginebrina y la múltiple participación. Su presencia en Ginebra fue motivo de disputas acaloradas en el ámbito local. El diputado socialista Joaquín Coca presentó como moción en el Congreso Nacional la necesidad de una invitación al Ministro del Interior Vicente Gallo para que informe lo sucedido sobre la designación de la delegación obrera a la conferencia de la OIT. Coca entendía que, en materia de designación de representantes obreros argentinos a las conferencias internacionales del trabajo, el gobierno "no se ajusta, no diré ya, a las normas establecidas por el tratado de Versalles, sino tampoco a las reglas más elementales de corrección” (Diputados, 1925, p. 164). En su relato ante la Cámara, cuenta que un año antes, en mayo de 1924, el Ministro de Relaciones Exteriores y Culto Ángel Gallardo había informado a su par en la cartera del Interior sobre la fecha y realización de la conferencia de 1925, con antelación. Luego de reiterar la información y el pedido de designación del delegado obrero en 5 oportunidades y misivas, la última fechada el 31 de marzo de 1925, el Ministro Gallo designó al católico Conei el 11 de mayo, a pocos días de iniciarse la conferencia. Coca advertía que esta situación extrema, justificada como sin alternativa por el propio DNT, configuraba la condición de posibilidad de designación de representantes sin consultar a los gremios y entidades obreras realmente representativas, frente al intento primero de colocar un representante considerado tal por el Gobierno Nacional y no por el movimiento sindical, como Lauzet, y luego al referente católico. Denunciaba además que en el "laborioso" proceso de designación el DNT recibió una nota de la Federación Obrera Molinera, proponiendo para delegado a la Conferencia Internacional del Trabajo al señor Luis Lauzet, propuesta que el Departamento hizo suya y elevó al Ministro del Interior.

El PS denunció en su periódico que tal representante no pertenecía a ese gremio, de existencia dudosa en palabras de los socialistas, ante lo cual el DNT retiró el pedido de nombramiento de Lauzet. Sin embargo, el 6 de junio Luis Lauzet viajó a Ginebra ya no como delegado obrero, sino como asesor técnico gubernamental de la delegación argentina. Coca sostenía que "se ve que se trata de esas personas que sirven lo mismo para un barrido que para un fregado" (Diputados, 1925, p. 167). Ante la injuria socialista sobre Lauzet, el diputado radical Tamborini argumentaba: "No es un delegado gubernamental, es un agravio injusto, porque al señor diputado le consta que ha estado toda su vida junto a las máquinas, que es un obrero auténtico.” (Diputados, 1925, p. 167).

El tema era presentado como denuncia de la liviandad y desconcierto con que el Poder Ejecutivo trataba las designaciones. En este sentido se denunciaba que al reclamar el pasaporte Lauzet no pudo obtenerlo porque no tenía libreta de enrolamiento, es decir, no era ciudadano argentino, nativo o naturalizado. La 
representación nacional se desmoronaba allí mismo, ante esta situación ignorada o pasada por alto por el gobierno. Tal ligereza era vista como un perjuicio para el orden social interno y para "nuestra seriedad en el exterior" (Diputados, 1925, p. 167). Finalmente, el pedido de informe al Ministro del Interior no fue aprobado, con 44 votos en contra de los 79 parlamentarios. De todas maneras, lo significativo del debate fue la centralidad política de la representación obrera, las disputas en torno a su nombramiento, y su rol central en la autorepresentación de nación seria y moderna, tanto hacia adentro como en esa "vidriera al mundo" y las naciones que constituía la OIT (Diputados, 1925, p. 167).

Tras su participación polémica como asesor técnico gubernamental en la conferencia de 1925, que le valió la expulsión de su gremio de origen, la Federación Gráfica Bonaerense, Lauzet publicó una obra íntegra sobre la historia, los antecedentes, el funcionamiento y su interpretación de la OIT. El libro, titulado Una creación obrera. El organismo Internacional del Trabajo. Su obra y porvenir, apuntaba a "señalar la decisiva influencia de la actividad obrera en la Creación del Organismo Internacional del Trabajo” (Lauzet, 1925, p. 12). Sus reflexiones definían un nuevo campo de intervención y una nueva actitud de las organizaciones sindicales (de algunas de ellas) hacia una nueva orientación menos doctrinaria, que interviene allí donde están en debate sus condiciones y derechos. De hecho, define al organismo ginebrino de manera positiva como la sanción universal de los derechos obreros, "la consagración práctica de uno de los principios básicos del movimiento obrero: el carácter universal" y la "forzosa necesidad de hallar soluciones en el orden internacional” (1925, p. 12). Así presentado, el internacionalismo proclamado por la OIT fue considerado como exponente de las virtudes creadoras del movimiento obrero internacional, que al mismo tiempo construía así una nueva herramienta para la transformación de las relaciones sociales, económicas y jurídicas. En tanto elemento de un nuevo periodo "constructivo" del movimiento obrero mundial, que dejaba así atrás las disputas doctrinarias, y haciendo bandera de un pragmatismo remarcable, Lauzet proponía a la entidad como el centro de una nueva política sindical, a la cual finalmente dedicaría su tiempo, esfuerzos y gestiones. Él mismo iba a convertirse en el agente viabilizador de las relaciones internacionales entre Argentina y la OIT al asumir como correspondiente al frente de la Oficina Nacional de Correspondencia de la OIT en Buenos Aires, fundada en 1932 por Raúl Migone, quien estuvo al frente de la misma hasta 1936. Alejandro Unsain le sucedió en el cargo como corresponsal de la OIT en Argentina, entre 1937 y mediados de 1940. Tal función, ya desplegada en otras latitudes de la región como en el notable caso de Moisés Poblete para Chile (Yañez Andrade, 2013), implicaba la búsqueda de información de los acontecimientos de la vida política y económica del país relevantes para la acción del organismo ginebrino, a la vez que apuntaba a constituirse como órgano fiscalizador de las convenciones y recomendaciones aprobadas en las conferencias, y de su ratificación por el gobierno nacional. $\stackrel{14}{~ L u i s ~ L a u z e t ~ f u e ~ q u i e n ~ a s u m i o ́ ~ e n ~ 1940, ~ t r a s ~ l a ~}$ salida de Unsain, y permaneció en su función hasta 1954. Tras su retiro, la Corresponsalía en Buenos Aires quedó vacante hasta que a comienzos de 1955 se hizo cargo de la misma Héctor Ruiz Moreno.

\section{Comentarios finales}

Los años 20, lejos de ser un período de plena desconfianza, puede ser caracterizado a la luz de los casos, tensiones y argumentos aquí expuestos como un periodo de alternantes disputas, impugnaciones y amplias expectativas, en el cual se delinearon nuevas fronteras -aún permeables- entre corrientes obreras con actitudes afines a la propuesta ginebrina y las que no, que generaron tensiones dentro de las organizaciones obreras, y las ubicaron en un lugar distintivo frente a los estados.

El caso argentino puede ser visto como un intento permanente de auto(re)presentación como modelo -una delegación completa, con fuerte representación obrera que denotara su modernidad y progreso- por parte de todos los componentes de su delegación. 
La designación de las representaciones fue motivo de controversias varias, entre los gremios y el gobierno, al interior del movimiento obrero, o de alguno de sus exponentes ante el organismo internacional. En cualquiera de sus versiones, la disputada designación muestra un campo de acción amplio y potente de las organizaciones obreras en este sentido.

La importancia de la delegación completa, con una representación tripartita, constituyó una fuente de legitimidad de la propia organización y su política, así como de la autopresentación por parte del gobierno y de los propios delegados obreros. Si enviar una delegación completa colocaba al país en un lugar destacado y prestigioso del concierto de naciones al interior del organismo, al mismo tiempo era presentado como signo de modernidad entre los propios delegados. Esto explica que, en una entrevista realizada en 1921 al director Albert Thomas, este resaltara "el interés que la Argentina le había despertado, acaso con motivo de ser uno de los pocos países sudamericanos que en los dos congresos internacionales ha tenido representación plena.” (La Nación, 5/10/1920, p. 4).

Es decir, la autorepresentación laudatoria que los delegados a Ginebra por la Argentina sostuvieron durante la década de 1920, encontraba en la OIT un reflejo complaciente. En ese aval internacional, la política argentina en relación a la cuestión obrera y los vínculos del Estado con las organizaciones sindicales y patronales, se veía reforzada. La ideología de la OIT en su afán reformista y progresivo, con énfasis en la conciliación de las clases, obtenía así un importante impulso.

\section{Notas}

1 En las páginas de las publicaciones periódicas del DNT, el Boletín del Departamento Nacional del Trabajo (BDNT) y la Crónica Mensual del Departamento Nacional del Trabajo (CMDNT), son recurrentes las actualizaciones de la legislación internacional, con especial foco en la situación europea, pero en donde se da cuenta también de la legislación australiana, de Nueva Zelanda y países de América Latina y Estados Unidos.

$\underline{2}$ Los informes de las conferencias de Washington y Génova fueron publicados en el BDNT en sus números 45 y 47 de febrero y septiembre de 1920. Los informes de la X Conferencia llevada adelante en Ginebra se publicaron por partes en los números 116, 117 y 118 de la CMDNT. Los delegados obreros a la VI Conferencia fue publicado en el número 82 de la CMDNT.

$\underline{3}$ El folleto se tituló Working acts and projects of the executive power: Argentine delegation to the International Conference in Washington. Desafortunadamente no ha sido posible consultarlo en razón de encontrarse el ejemplar en la biblioteca de la OIT en Ginebra. Por referencias secundarias se puede sostener que el mismo era una compilación de las leyes laborales vigentes, así como algunos proyectos legislativos que con posterioridad serían incorporados al proyecto de Código del Trabajo de 1921 confeccionado por el propio Unsain.

4 Sobre la actuación de Unsain en las primeras Conferencias ver Caruso (2014) y Stagnaro (2017).

$\underline{5}$ Se mencionan sólo a aquellos que participaron por primera vez en la década del veinte, pero estas continuidades son observables también en las décadas del treinta y el cuarenta.

6 La Fraternidad era el sindicato del personal de locomotoras -maquinistas y fogoneros-, a la razón uno de los sindicatos más fuertes y con una sólida organización a nivel nacional. Al decir de Belloni Ravest (1969, p. 11) el interés de La Fraternidad en la OIT se debía a que como sindicato grande y serio (sic) ya estaba inmiscuido en cuestiones de índole internacional. 
$\underline{7}$ "several organizations of more or less the same size and influence”. Traducción propia

$\underline{8}$ "At the present time it has two members, its secretary and its treasurer, who are making a trip to Europe on behalf of their organization to study the different forms of union organization which exist in all the countries of Europe. I am surprised that such an organization can be said to have merely an ephemeral life when it sends two men to visit Europe for six months.” Traducción Propia

$\underline{9}$ "would injure a Government which has endeavored from the very outset to carry out the ideal of the League of Nations and the International Labor Organization, for the benefit, [...] of those masses of men who, though contributing by their work to the welfare of the community, have now only poverty and misery in store.” Traducción Propia

10 "and at the same time defend the dignity of the Argentine government” Traducción Propia

$\underline{11}$ “never in any way used its power to the detriment of national economic welfare” Traducción Propia

12 Oudegeest no detuvo su ataque contra Baliño y arremetió contra el supuesto carácter legalista de La Fraternidad. Sostuvo irónicamente "According to the information given by the representative of the workers of Argentina at the conference, the fact that they never engaged in revolutionary activities was a great argument in their favor, but that is probably the reason the Goverment of Argentina chose them, considering them the best behaved of the lot," (OIT, 1920, p. 112). Entre los votos favorable a rechazar la credencial a Baliño estuvo el del español Francisco Largo Caballero, de la Unión General de Trabajadores de España, quien sin embargo sostenía una buena relación con Alejandro Unsain por medio de su colaborador Antonio Fabra Rivas. (Martin-Sánchez, 2017)

$\underline{13}$ Ginebra fue finalmente la sede del organismo, y allí se realizan las conferencias anuales.

14 Sobre Migone ver Ferreras, 2008.

\section{Bibliografía}

Belloni Revest, H. (1969). El sindicalismo argentino en la Organización Internacional del Trabajo. Buenos Aires: S/E.

Calvo Caballero, P. (1998). La OIT, universo mental y encrucijada de hechos. actitudes de patronos y obreros socialistas en los primeros años de su funcionamiento. Studia histórica contemporánea, 16, Universidad de Salamanca, España, 167-184.

Caruso, L. (2017). Legislando en aguas profundas. La OIT, nuevas reglas para el trabajo marítimo y su desarrollo en la Argentina de la primera posguerra. En Caruso, L. y Stagnaro, A. (coord.), Regular y Legislar el mundo del trabajo Latinoamericano. Aportes para una historia regional de la OIT. La Plata: FaHCE.

Caruso, L. (2014). La política laboral argentina en la inmediata posguerra: una perspectiva internacional, 1907-1925. Revista Relaciones, estudios de historia y sociedad, 138, 11-43

Caruso, L. (2011). Estado, armadores y clase obrera en la Argentina de entreguerras: la segunda Conferencia de la OIT sobre trabajo marítimo (1920), Anuario IEHS, 26, 1-23.

Diaz, H. (2008). Ramón Suárez Picallo. Años de Formación Política. Selección de textos (1916-1931). Buenos Aires: Editorial Alborada.

Di Tella, T. (2003). Perón y los sindicatos. El inicio de una relación conflictiva. Buenos Aires: Ariel. 
Ferreras, N. O. (2012). La construcción de una Communitas del Trabajo: las relaciones de la Organización Internacional del Trabajo (OIT) y América del Sur durante la década de 1930. Dimensões, 29, 3-21.

Ferreras, N. O. (2011). Entre a expansáo e a sobrevivencia: a viagem de Albert Thomas ao Cone Sul da América. Antíteses, 4(7), 127-150.

Ferreras, N. O. (2008). ¿El inicio de una larga amistad? Los primeros pasos en la relación entre la Organización Internacional del Trabajo y la Argentina (1931 a 1937). XXI Jornadas de Historia Económica Asociación Argentina de Historia Económica. UNTREF, Buenos Aires. Recuperado de http://xxijhe.fahce.unlp.edu.ar

Godio, J.y Wachendorfer, A. (1986). Las internacionales sindicales. Nueva Sociedad, 83, 81-88.

Gordillo, M. (1988). La Fraternidad en el movimiento obrero: un modelo especial de relación (1916-1922). Buenos Aires: CEAL.

Martín-Sánchez, J. (2017). La revista Informaciones Sociales: la OIT y Argentina en la latinoamericanización de la cuestión social en los años veinte. En González Leandri, R. y Suriano, J. (eds.), La Cuestión Social y sus itinerarios de difusión a través de las publicaciones periódicas argentinas, 18701930. Rockville-MD US: Global South Press.

Monserrat, M. A. (2011). Los trabajadores ferroviarios: sus luchas y organizaciones sindicales en el contexto de la Argentina gobernada por el radicalismo. (1916-1930). Cuadernos del Ciesal, 8 (10), 97-118.

Rodgers, G.; Lee, E.; Swepston, L. y Van Daele, J. (2009). La Organización Internacional del Trabajo y la lucha por la justicia social, 1919-2009. Ginebra, OIT.

Stagnaro, A. (2017). Profecía autocumplida: la delegación argentina en Washington entre el prestigio internacional y la acción local. En Caruso, L. y Stagnaro, A. (coord.), Regular y Legislar el mundo del trabajo Latinoamericano. Aportes para una historia regional de la OIT. La Plata: FaHCE.

Suriano, J. (2012). El Departamento Nacional del Trabajo y la política laboral durante el primer gobierno de Hipólito Yrigoyen. En Plotkin, M.B. y Zimmerman, E. (comp.), Los Saberes del Estado. Buenos Aires: Edhasa.

Suriano, J. (1991). Estado y conflicto social: el caso de la huelga de maquinistas ferroviarios de 1912. Boletín del Instituto de Historia Argentina y Americana Dr. E. Ravignani, 4, 91-115.

Troncoso, O. (1983). Fundadores del gremialismo obrero. Buenos Aires: CEAL.

Van Daele, J. (2010). Writing ILO Histories: a State of the Art. En Van Daele, J., Rodriguez Garcia, M., Van Goethem, G. y Van Der Linden, M., Essays on the International Labour Organization and Its Impact on the World during the Twentieth Century. Bern: Ed. Peter Lang.

Yañez Andrade, J. C. (2013). La OIT y la red sudamericana de corresponsales. El caso de Moisés Poblete. En Herrera León, F. y Herrera González, P. (coord.), América Latina y la Organización Internacional del Trabajo. Redes, cooperación técnica e institucionalidad social 1919-1950. Michoacán: UMSNH, UM, UFF.

Yañez Andrade, J. C. (2000). Chile y la Organización Internacional del Trabajo (1919-1925). Hacia una legislación social universal. Revista de Estudios Históricos-Jurídicos, 22. Recuperado de http://dx.doi.org/10.4067/S0716-54552000002200014 


\section{Fuentes}

Anastasi, L. y Espil, F. (1920). Liga de las naciones, conferencia internacional del Trabajo. Sesión de Washington, Octubre de 1919, informe presentado al gobierno argentino por los delegados doctores Leonidas Anastasi y Felipe Espil. Buenos Aires: Gráfica A. de Martino.

Lauzet, L. (1925). Una creación obrera. El organismo Internacional del Trabajo. Su obra y porvenir. Buenos Aires: Editorial Jurídica.

Boletín del Departamento Nacional del Trabajo, varios números.

Crónica Mensual del Departamento Nacional del Trabajo, varios números.

Diputados (1925). Diario de Sesiones (Tomo 3). Buenos Aires: Imprenta de Congreso de la Nación.

La Fraternidad

Organización Internacional del Trabajo (OIT). (1920). International Labor Conference.Washington: Government Printing Office.

Organización Internacional del Trabajo (OIT). (1929). Cláusulas de los tratados de paz relativas al trabajo. Ginebra: Oficina Internacional del Trabajo.

USA (1926) Unión Sindical Argentina. Memoria y balance del Comité Central, diciembre 1925. 